\title{
Optimization and Characterization of Bio-oil Produced from Rice Husk Using Surface Response Methodology
}

\section{Ige Ayodeji Rapheal*a, Elinge Cosmos Mokia, Aliyu Muhammada, Gwani Mohammed ${ }^{b}$, Lawal Hassan Gusauc}

a Department of Pure and Applied Chemistry, Kebbi State University of Science and Technology, Aliero, Kebbi State, Nigeria.

b Department of Physics, Kebbi State University of Science and Technology, Aliero, Kebbi State, Nigeria.

c Department of Pure and Applied Chemistry, Usmanu Danfodiyo University, Sokoto, Nigeria.

* Corresponding author email: igeayodeji2@gmail.com.

\section{DOI: 10.2478/acmy-2021-0003}

\section{Abstract:}

The study depicts the production, optimization and characterization of bio-oil from pyrolyzed rice husk using a fabricated fixed bed reactor. The pyrolysis process was conducted with bio-oil response, bio-char response and non-condensable gases response as products. The effect of pyrolysis variables were observed by the production of the bio-oil as the response. Sixty runs of pyrolysis experiments were suggested by Box Benkhen design indicated optimum pyrolysis conditions at particle size of $2.03 \mathrm{~mm}$ mesh, reaction time of $81.80 \mathrm{mins}$ and temperature of $650^{\circ} \mathrm{C}$ for rice husk. The maximum bio-oil yield was obtained with 38.39\% at optimum condition of the variables. The bio-oil sample obtained had better performance compared with ASTM standard. Such a determination would contribute so immensely to a significant comprehension of the chemical efficiency of the pyrolysis reaction.

Keywords: Pyrolysis, Rice husk, Temperature, Particle size, Reaction time

\subsection{Introduction:}

Production of bio-oil from various biomass resources and its application are attracting notable attention globally [1]. The decline in the dependency on fossil fuels, diminishing of greenhouse gas emissions and reduction of environmental problems from the exploration and usage of fossil fuels are the aspiring goals that have resulted in research efforts in developing technologies to produce more energy from renewable resources such as biomasses [2]. Pyrolysis process has been developed for over a decade as the most promising thermochemical process to produce energy from the biomass [3]. Pyrolysis is a process of heating biomass material in a close vessel without infiltration of oxygen while three major products are gotten which is bio-oil, bio-char and noncondensable gases $[4,5]$. Influence of oil crisis necessitates the need to search for efficacious renewable sources of energy. Nigeria is an agro-industry base country which has plentiful supply of a variety of biomasses with limited use. Therefore, it is necessary to make use of biomass residues derived from industrial and agricultural processes for energy production through pyrolysis process which can serve as an alternative source of fuel [5]. Pyrolysis biomass residues can help meet renewable energy targets by displacing fossil fuels and, thereby, deal with concerns about global warming [5].

Pyrolysis offers more scope for recovering products from forestry and agricultural wastes than simply burning it. When both residues are burnt directly in a furnace/boiler, the only practical product is heat; however, when they are Pyrolyzed, bio-oil, gases and bio-char can not only be used as a fuel but can also be purified and used as a feedstock for petrochemicals and other applications [5]. Rice husk is a form of lignocelluloses biomass and it is renewable waste, containing $28-30 \%$ inorganic and $70-72 \%$ organic compounds [6]. The Nigerian government recently came up with a policy decision in 2019 to ban rice importation completely. It is very obvious that the foreign rice in Nigerian markets now depreciating due to border closure against smuggling and there is an increase in rice production in Nigeria. A more environmentally friendly approach and concerted efforts are needed to implement this habit of converting this waste into useful products [7]. The aim of this research is to optimize and characterize bio-oil produced from rice husk using surface response methodology. The specific objectives are to determine the maximum bio-oil yield at optimum pyrolysis conditions using surface response methodology, to determine the physicochemical properties of the bio-oil produced and fuel properties of the bio-oil produced.

\subsection{Materials and Methods}

\subsection{Materials}

The rice husks were collected from Aliero, Aliero Local Government Area, Kebbi State, Nigeria. The rice husks were pulverized and rinsed with tap water to remove impurities and were dried in the oven at $105^{\circ} \mathrm{C}$ for $24 \mathrm{hr}$. The dried pulverized biomass was stored in air-tight containers until further use [8].

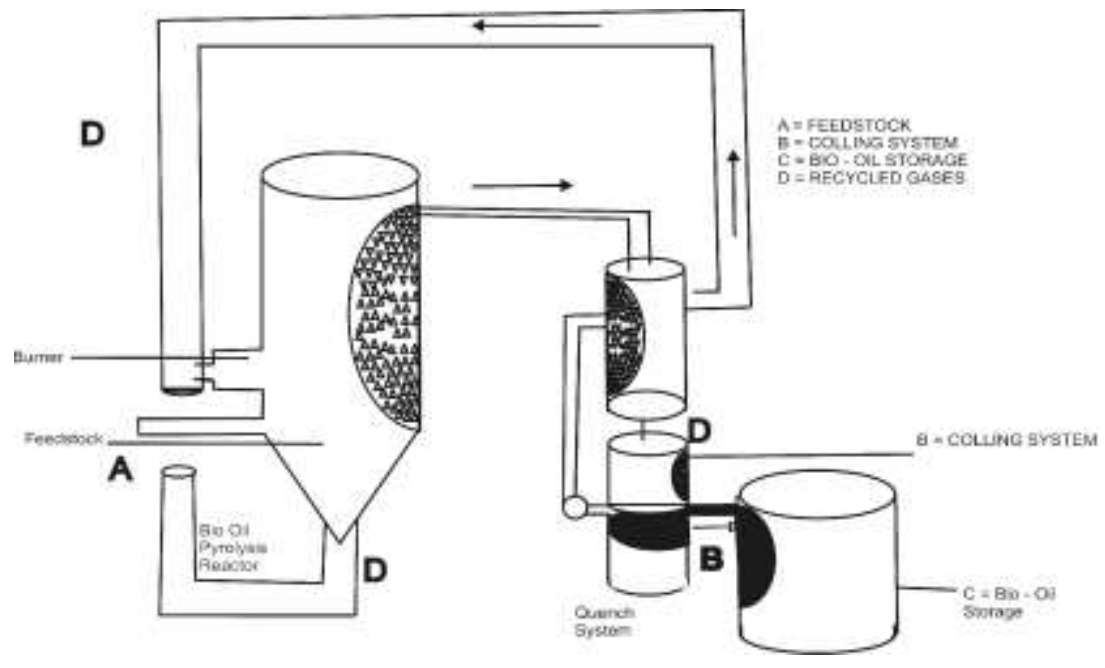

Figure 1. Schematic Diagram of Fabricated Pyrolysis Reactor 


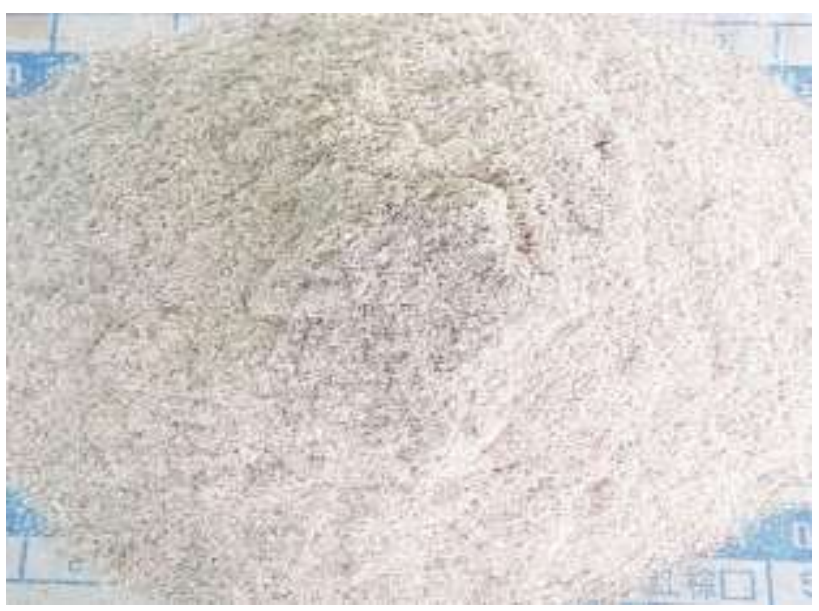

Figure 2. Rice husk sample

\subsection{Methods}

\subsubsection{Sample Preparation}

Fabricated Pyrolytic chamber was use (Figure 1) for the extraction of rice husk. The reactor was made from stainless steel plate to prevent rusting, also connected to a glassware condenser for condensation process with reactor fixed stock capacity of $1 \mathrm{Kg}$ and electrical heater capacity $1 \mathrm{Kw}$. $1 \mathrm{Kg}$ of the rice husks were filled into the reactor which was connected to a condenser. The evolving gases were distilled in the condenser to form bio-oil and were collected inside a conical flask. The fabricated fixed bed reactor is without the solid catalyst particles being loaded. This is to determine the efficiency of the reactor on the yield and quality of bio-oil produced without using catalyst and also to save cost.

The formula below was adopted for yield calculation by [9].

$$
\text { Bio - oil Yield }(\%)=\frac{\text { weight. of liquid produced }}{\text { weight of incipient py roly sismaterial }} \times 100 \ldots \ldots \ldots \ldots \ldots \ldots 1
$$

Solid Yield $(\%)=\frac{\text { weight. of solid produced }}{\text { weight of incipient pyroly sismaterial }} \times 100 \quad \ldots \ldots \ldots \ldots \ldots \ldots . . .2$

Non Condensable Gases $=100-($ Solid Yield + Liquid Yield $) \ldots . .3$

\subsubsection{Experimental Design}

Response surface methodology (Box-Behnken) was used for the optimization experiments using Minitab 17 statistical software at a D 0.05(95\% confidence level) according to [10]. Self-standing parameters such as temperature, particle size and time were chosen for the inquiry. The runs were wholly randomized to procure at sum of 60 runs to determine the efficiency and sustainability of the optimum parameters.

Table 1. Optimization Processes Variables

\begin{tabular}{lll}
\hline Factor & Lower Level & Upper Level \\
\hline Particle Size $(\mathrm{mm})$ & 1.00 & 4.00 \\
Temperature $\left({ }^{\circ} \mathrm{C}\right)$ & 500 & 650 \\
Time $(\mathrm{min})$ & 30 & 120 \\
\hline
\end{tabular}

\subsubsection{Determination of Physico-chemical Properties}

The physic-chemical properties of the maximum bio-oil yield produced using response surface methodology were evaluated.

\subsubsection{1. pH Determination}

To evaluate the corrosive property of the bio-oil products, the $\mathrm{pH}$ of the bio-oil was measured using a pH meter from Eutech Instruments. The sample size of bio-oil was 1-2 ml. The recorded value is the final result, expressed as a $\mathrm{pH}$ of bio-oil.

\subsubsection{Determination of Moisture content ASTM D 1744}

The moisture content of the bio-oil was determined using Karl Fischer Titrator, type 784 KFP Titrino, Metrohm was according to [12]ASTM D 1744 (1988). The bio-oil was titrated with standard Karl Fischer reagent to an electrometric end point.

\subsubsection{Ash Content}

The ash content of the bio-oil sample was determined using [13] procedure which is calculated using formula 4.

Ash Content $=\frac{M a-M o}{M s} \times 100 \ldots \ldots \ldots . . .4$

Where, $\mathrm{Ma}=$ Mass of crucible plus ash, $\mathrm{Mo}=$ Mass of empty crucible, Ms= Mass of sample 


\subsubsection{Density Determination of bio-oil from Groundnut Shell ASTM D (American Standard Test Method) 4052,}

The density of a material is defined as mass per unit volume of sample and this was determined according to [14] using digital density analyser. Firstly, the density meter was calibrated by water at $25^{\circ} \mathrm{C}$ before measurement in order to minimize the errors. Then, $1 \mathrm{ml}$ of biooil was injected into the density meter at $25^{\circ} \mathrm{C}$ and repeated three times. The average value is the final result, expressed as density in $\mathrm{g} / \mathrm{cm}^{3}$.

\subsubsection{Determination of Acid Value}

The acid value of the groundnut shell bio-oil sample was determined according to [14] using equation (5).

$A . V=\frac{56.1 \times V \times M}{m} \ldots \ldots \ldots . . .5$

Where $V=$ volume of $\mathrm{KOH}$ used; $M=$ molarity of $\mathrm{KOH}$ and $m=$ mass of sample.

\subsubsection{Determination of Fuel Properties}

The fuel properties of the maximum bio-oil yield produced using response surface methodology were determined.

\subsubsection{Gross calorific value of bio-oil from Groundnut Shell (ASTM D-482-07)}

The gross calorific value is a measure of the quantity of heat released in total combustion and therefore, measures the energy content of a fuel. The calorific value of bio oil was determined by burning a weighed sample in an oxygen-bomb calorimeter, Leco AC-350 under controlled conditions based on [15] procedure. The test procedure consists of adding the weighed of bio oil samples to the cup (approximately $0.5-1.0 \mathrm{ml}$ ), installing a fuse, and charging the bomb with oxygen to approximately $200 \mathrm{psi}$. The heat of combustion was computed from temperature observations before, during, and after combustion, with proper allowance for thermo-chemical and heat transfer corrections. It is the most important fuel property of any liquid fuel.

\subsubsection{Kinematic viscosity at $40^{\circ} \mathrm{C}$ (ASTM D 445-06)}

A viscometer was placed into a water bath with an adjustable temperature and remained for 30 minutes. The bio-oil was coalesce to the viscometer and was left in the water bath to reach the thermometer. Bio-oil was permitted to flow excellently and the time demanded for the meniscus to pass from the first mark several times to ascertain an average value was the multiplied with the viscometer calibration according to [16].

\subsubsection{Flash point (ASTM D 93-08)}

Flash point is a measure of the liquid temperature necessary for the vapours above a pool of the fuel to ignite by passing a flame through the vapours. This is also a measure of the volatility of the oil, as well as its ease of ignition. The higher this number, the safer the oil is to handle because the risk of accidental vapor ignition is reduced. The flash point was determined using [17] by heating a sample of the fuel in a stirred container and passing a flame over the surface of the liquid. At temperature at or above the flash point, the vapour ignited and an easily detectable flash was observed. It is an index of fire risk during storage under ambient conditions. A sample is deemed to have flashed when a large flame appears and instantaneously propagates itself over the entire surface of the test specimen.

\subsubsection{Pour point (ASTM D 97-11)}

The pour point is the lowest temperature at which the liquid is observed to flow under prescribed conditions. This parameter is an indication of the minimum temperature at which the oil can be pumped without heating the storage tank. The bio-oil sample was restrained in the freezer at about $500{ }^{\circ} \mathrm{C}$ them placed in a heating mantle to melt. The temperature at which the bio-oil begins to pour was determined as pour point according to [18].

\subsection{Results}

\subsection{Analysis of variance}

Model: These tests whether the terms in the model have any effect on the response; for regression model to be significant $(\mathrm{P}<0.05)$. The $\mathrm{P}$-value observed was $(\mathrm{P}=0.000)$ which is a clear indication that, at least one of the terms in the model has an impact on the mean response. Model is further broken into different orders of terms in the model namely; linear, square, and interaction effect.

Linear effect; for temperature $(\mathrm{P}=0.000)$ is less than 0.05 . Therefore, temperature has linear effect on the model whereas $\mathrm{P}$-value for particle size $(\mathrm{P}=0.604)$ is greater than $(\mathrm{P}<0.05)$ and time $(\mathrm{P}=0.000)$ is less than $(\mathrm{P}<0.05)$ which shows that time has linear effect on the model and particle size has no linear effect on the model.

Squared effects: Squared terms are used to evaluate whether or not there is curvature in the response surface. The p-value of 0.000 for the squared effects is less than 0.05 . Therefore, there is significant evidence of a quadratic effect. The individual p-values for temp*temp, particle size*particle size and time*time and are $0.139,0.058,0.000$ respectively, indicating that the relationships between temperature and yield and particle size and yield does not follows a curved line.

Interaction effects: The p-value of 0.118 is more than 0.05 ; therefore, there is no significant evidence of interaction effects. The temperature by time interaction is less than 0.05 . Therefore, there is a significant interaction effect. That is, the effect of temperature on reaction yield depends on the time.

\subsection{Model Summary}

$\mathrm{S}, \mathrm{R}^{2}$ adjusted, $\mathrm{R}^{2}$, and $\mathrm{R}^{2}$ predicted are measures of how well the model fits the data. These values can help you select the model with the best fit.

$S$; is measured in the units of the response variable and represents the standard distance that data values fall from the regression line. For a given study, the better the equation predicts the response, the lower $\mathrm{S}$ is.

$\mathrm{R}^{2}$; describes the amount of variation in the observed response values that is explained by the predictor(s). $\mathrm{R}^{2}$ always increases with additional predictors $\mathrm{R}^{2}$ adjusted; is a modified $\mathrm{R}^{2}$ that has been adjusted for the number of terms in the model. If you include unnecessary terms, $\mathrm{R}^{2}$ can be artificially high Unlike $\mathrm{R}^{2}$ adjusted $\mathrm{R}^{2}$ may get smaller when you add terms to the model. Use $\mathrm{R}^{2}$ adjusted to compare models with different numbers of predictors.

$\mathrm{R}^{2}$ predicted; is a measure of how well the model predicts the response for new observations. Large differences between Predicted $\mathrm{R}^{2}$ and the other two $\mathrm{R}^{2}$ statistics can indicate that the model is overfit. An overfit model does not predict new observations nearly as well as the model fits the existing data. Predicted $\mathrm{R}^{2}$ is more useful than adjusted $\mathrm{R}^{2}$ for comparing models because it is calculated with observations not included in the model calculation.

$$
\mathrm{R}^{2} \quad \mathrm{R}^{2} \text { (adj) } \quad \mathrm{R}^{2} \text { (pred) }
$$

$1.70489 \quad 83.51 \% \quad 80.54 \% \quad 76.23 \%$


For the pyrolysis data, $83.51 \%$ of the variation in yield is explained by model, the predicted $\mathrm{R}$ is $76.23 \%$, and the adjusted $\mathrm{R}$ is $80.54 \%$. The lower $\mathrm{R}^{2}$ may indicate that the model is over-fit and suggests that the model will not predict new observations nearly as well as it fits the existing data.

Contour Plot of Bio-oil Yiel vs Particle Size (mm); Temperature (0C)

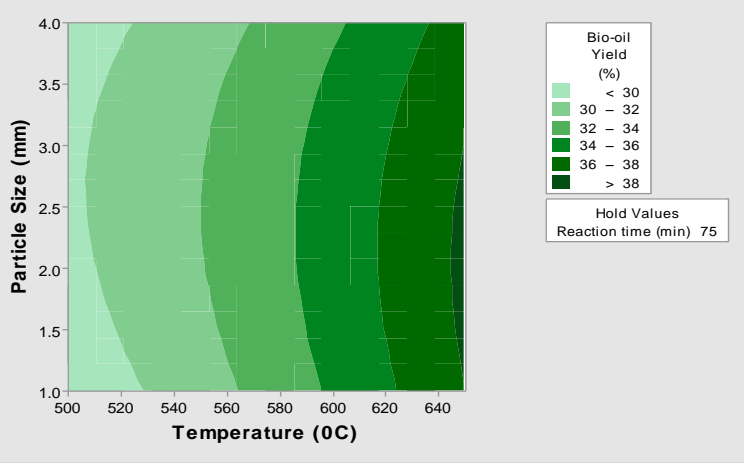

Figure 3. Contour plot showing the combined effect of bio-oil yield on particle size and temperature when time held constant for rice husk.

Contour Plot of Bio-oil Yiel vs Particle Size (mm); Reaction time (min
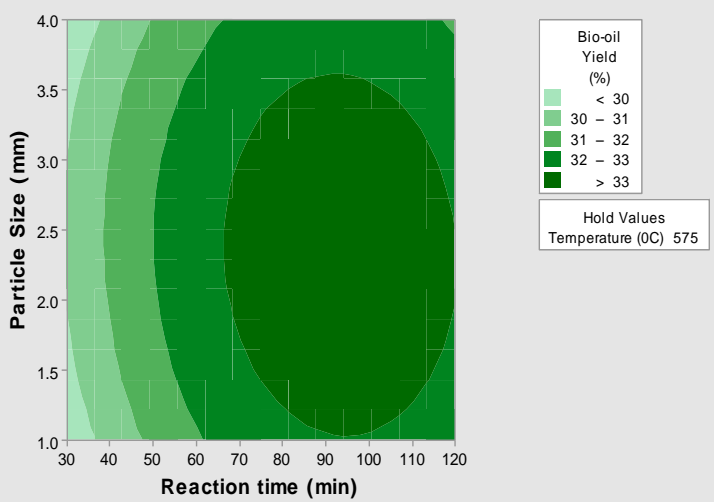

Figure 4. Contour plot showing the combined effect of bio-oil yield on particle size and time when temperature constant for rice husk.

Contour Plot of Bio-oil Yiel vs Reaction time (min); Temperature (0C)
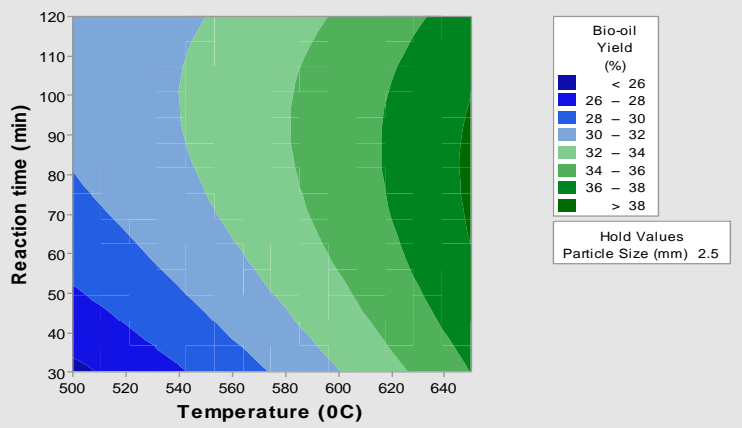

Figure 5. Contour plot showing the combined effect of bio-oil yield on reaction time and temperature when particle size constant for rice husk.

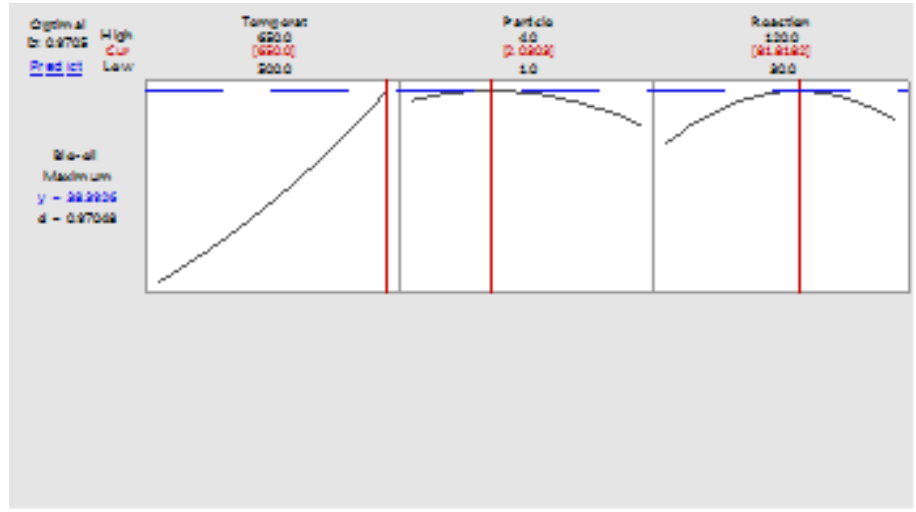

Figure 6. Optimization Plot for Rice Husk. 
ISSN: 2576-6732 (Print)

Table 2. Experimental Design Matrix and Results of Rice Husk (Pyrolysis Yield) from the Experimental Runs.

\begin{tabular}{|c|c|c|c|c|c|c|}
\hline $\begin{array}{c}\text { Run } \\
\text { Order }\end{array}$ & $\begin{array}{c}\text { Temperature } \\
(0 \mathrm{C})\end{array}$ & $\begin{array}{c}\text { Particle } \\
\text { Size }(\mathrm{mm}) \\
\end{array}$ & $\begin{array}{l}\text { Reaction time } \\
\text { (min) }\end{array}$ & Bio-oil Yield (\%) & $\begin{array}{c}\text { Bio-char yield } \\
(\%)\end{array}$ & NCG yield (\%) \\
\hline 1 & 575 & 2.5 & 75 & 32.83 & 42.56 & 24.61 \\
\hline 2 & 575 & 2.5 & 75 & 32.83 & 42.57 & 24.60 \\
\hline 3 & 575 & 1 & 120 & 31.53 & 43.87 & 24.60 \\
\hline 4 & 575 & 2.5 & 75 & 32.82 & 42.56 & 24.62 \\
\hline 5 & 500 & 1 & 75 & 29.79 & 46.40 & 23.81 \\
\hline 6 & 650 & 2.5 & 30 & 35.82 & 39.44 & 24.74 \\
\hline 7 & 575 & 1 & 30 & 30.12 & 45.20 & 24.68 \\
\hline 8 & 500 & 4 & 75 & 29.30 & 47.25 & 23.45 \\
\hline 9 & 500 & 2.5 & 120 & 28.10 & 48.71 & 23.19 \\
\hline 10 & 650 & 2.5 & 120 & 37.38 & 38.11 & 24.51 \\
\hline 11 & 575 & 4 & 120 & 31.03 & 44.23 & 24.74 \\
\hline 12 & 500 & 1 & 75 & 29.78 & 46.41 & 23.81 \\
\hline 13 & 575 & 4 & 30 & 30.11 & 45.00 & 24.89 \\
\hline 14 & 575 & 4 & 120 & 31.02 & 44.22 & 24.76 \\
\hline 15 & 500 & 2.5 & 120 & 28.11 & 48.70 & 23.19 \\
\hline 16 & 500 & 2.5 & 30 & 24.02 & 54.46 & 21.52 \\
\hline 17 & 575 & 2.5 & 75 & 32.83 & 42.55 & 24.62 \\
\hline 18 & 575 & 2.5 & 75 & 32.84 & 42.57 & 24.59 \\
\hline 19 & 650 & 1 & 75 & 38.48 & 37.02 & 24.50 \\
\hline 20 & 650 & 2.5 & 30 & 35.83 & 39.44 & 24.73 \\
\hline 21 & 575 & 4 & 30 & 30.10 & 45.02 & 24.88 \\
\hline 22 & 575 & 1 & 120 & 31.54 & 43.86 & 24.60 \\
\hline 23 & 575 & 1 & 30 & 30.13 & 45.21 & 24.66 \\
\hline 24 & 650 & 4 & 75 & 36.21 & 38.59 & 25.20 \\
\hline 25 & 650 & 2.5 & 120 & 37.39 & 38.11 & 24.50 \\
\hline 26 & 575 & 2.5 & 75 & 32.82 & 42.57 & 24.61 \\
\hline 27 & 500 & 4 & 75 & 29.31 & 47.24 & 23.45 \\
\hline 28 & 500 & 2.5 & 30 & 24.01 & 54.45 & 21.54 \\
\hline 29 & 650 & 1 & 75 & 38.49 & 37.00 & 24.51 \\
\hline 30 & 650 & 4 & 75 & 36.21 & 38.58 & 25.21 \\
\hline 31 & 575 & 2.5 & 75 & 32.82 & 42.56 & 24.62 \\
\hline 32 & 575 & 2.5 & 75 & 32.83 & 42.56 & 24.61 \\
\hline 33 & 575 & 1 & 120 & 31.54 & 43.86 & 24.60 \\
\hline 34 & 575 & 2.5 & 75 & 32.84 & 42.57 & 24.59 \\
\hline 35 & 500 & 1 & 75 & 29.77 & 46.40 & 23.83 \\
\hline 36 & 650 & 2.5 & 30 & 35.80 & 39.45 & 24.75 \\
\hline 37 & 575 & 1 & 30 & 30.12 & 45.20 & 24.68 \\
\hline 38 & 500 & 4 & 75 & 29.31 & 47.26 & 23.43 \\
\hline 39 & 500 & 2.5 & 120 & 28.10 & 48.70 & 23.20 \\
\hline 40 & 650 & 2.5 & 120 & 37.37 & 38.11 & 24.52 \\
\hline 41 & 575 & 4 & 120 & 31.02 & 44.22 & 24.76 \\
\hline 42 & 500 & 1 & 75 & 29.78 & 46.41 & 23.81 \\
\hline 43 & 575 & 4 & 30 & 30.12 & 45.01 & 24.87 \\
\hline 44 & 575 & 4 & 120 & 31.02 & 44.22 & 24.76 \\
\hline 45 & 500 & 2.5 & 120 & 28.09 & 48.71 & 23.20 \\
\hline 46 & 500 & 2.5 & 30 & 24.01 & 54.45 & 21.54 \\
\hline 47 & 575 & 2.5 & 75 & 32.83 & 42.57 & 24.60 \\
\hline 48 & 575 & 2.5 & 75 & 32.84 & 42.56 & 24.60 \\
\hline 49 & 650 & 1 & 75 & 38.47 & 37.01 & 24.52 \\
\hline 50 & 650 & 2.5 & 30 & 35.81 & 39.44 & 24.75 \\
\hline 51 & 575 & 4 & 30 & 30.11 & 45.00 & 24.89 \\
\hline 52 & 575 & 1 & 120 & 31.53 & 43.86 & 24.61 \\
\hline 53 & 575 & 1 & 30 & 30.12 & 45.21 & 24.67 \\
\hline 54 & 650 & 4 & 75 & 36.20 & 38.59 & 25.21 \\
\hline 55 & 650 & 2.5 & 120 & 37.38 & 38.10 & 24.52 \\
\hline 56 & 575 & 2.5 & 75 & 32.82 & 42.56 & 24.62 \\
\hline 57 & 500 & 4 & 75 & 29.31 & 47.26 & 23.43 \\
\hline 58 & 500 & 2.5 & 30 & 24.03 & 54.48 & 21.49 \\
\hline 59 & 650 & 1 & 75 & 38.48 & 37.00 & 24.52 \\
\hline 60 & 650 & 4 & 75 & 36.21 & 38.59 & 25.20 \\
\hline
\end{tabular}


Table 3. Result of Variance for Rice Husk Bio-oil yield (\%)

\begin{tabular}{llllll}
\hline Source & DF & Adj SS & Adj MS & F-Value & P-Value \\
\hline Model & 9 & 735.895 & 81.766 & 28.13 & 0.000 \\
Linear & 3 & 652.945 & 217.648 & 74.88 & 0.000 \\
Temp. & 1 & 585.248 & 585.248 & 201.35 & 0.000 \\
Particle size & 1 & 0.794 & 0.794 & 0.27 & 0.604 \\
Time & 1 & 66.904 & 66.904 & 23.02 & 0.000 \\
Square & 3 & 65.019 & 21.673 & 7.46 & 0.000 \\
Temp*Temp & 1 & 6.583 & 6.583 & 2.26 & 0.139 \\
P. size*P. size & 1 & 10.968 & 10.968 & 3.77 & 0.058 \\
Time*Time & 1 & 46.265 & 46.265 & 15.92 & 0.000 \\
2-way interaction & 3 & 17.931 & 5.977 & 2.06 & 0.118 \\
Temp*P. size & 1 & 2.295 & 2.295 & 0.79 & 0.378 \\
Temp*Time & 1 & 15.386 & 15.386 & 5.29 & 0.026 \\
P. size*Temp & 1 & 0.250 & 0.250 & 0.09 & 0.771 \\
Error & 10 & 0.012 & 0.012 & & \\
Total & 20 & 0.023 & 0.023 & & \\
\hline DF & & & & &
\end{tabular}

$\mathrm{DF}=$ degree of freedom, Adj SS = adjusted sum of squares, Adj MS = adjusted mean squares,

$\mathrm{F}=\mathrm{F}$-statistics, $\mathrm{P}=\mathrm{p}$-value, and $\mathrm{S}=$ statistically significant

Regression Equation in Uncoded Units

Bio-oil Yield (\%) = $12.6-0.0493$ Temperature (0C) +3.88 Particle Size (mm) +0.3349 Reaction time (min)

+ 0.000119 Temperature (OC)*Temperature (0C) - 0.383 Particle Size (mm)*Particle Size (mm)- 0.000874 Reaction time (min)*Reaction time (min) -

0.00337 Temperature (OC)*Particle Size (mm) - 0.000291 Temperature (OC)*Reaction time (min) - 0.00185 Particle Size (mm)*Reaction time (min)

Table 4. Physicochemical properties of bio-oil

\begin{tabular}{llllll}
\multicolumn{2}{l}{ Table 4. Physicochemical properties of bio-oil } & & & \\
\hline Bio-oil Samples & Ash Content (\%) & $\begin{array}{l}\text { Density } \\
\left(\mathbf{g} / \mathbf{c m}^{3}\right)\end{array}$ & pH & $\begin{array}{c}\text { Moisture } \\
\text { content (\%) }\end{array}$ & Acid Value \\
\hline Rice Husk & $0.02 \pm 0.04$ & $1.14 \pm 0.30$ & $3.69 \pm 0.20$ & $27.21 \pm 0.02$ & $14.18 \pm 0.20$ \\
\hline
\end{tabular}

Values are mean standard deviation of triplicate results

Table 5. Fuel properties of bio-oil

\begin{tabular}{lllll}
\hline Bio-oil Samples & $\begin{array}{c}\text { Kinematic } \\
\text { Viscosity (Cot } \\
\left(\mathbf{m m}^{2} / \mathbf{s}\right) \text { ) }\end{array}$ & Flash Point $\left({ }^{\circ} \mathbf{C}\right)$ & Pour Point $\left({ }^{\circ} \mathbf{C}\right)$ & $\begin{array}{l}\text { Calorific Value } \\
(\mathbf{M j} / \mathbf{k g})\end{array}$ \\
\hline Rice Husk & $29.30 \pm 0.25$ & $119.00 \pm 0.00$ & $-12.00 \pm 0.00$ & $40.75 \pm 0.33$ \\
\hline
\end{tabular}

Values are mean standard deviation of triplicate results

\subsection{Discussion}

Bio-oil yield optimization was investigated using Minitab 17 statiscal software. Figure 3 to figure 5 reveals three optimal variables procured from the optimization. Bio-oil yield of $38.39 \%$ for rice husk was achieved from justifiable experiments conducted at the levels of the process variables suggested. The $\mathrm{pH}$ of bio-oil from the feedstock was within the conventional bio-oil range of 2-3.8 because of organic acids mostly acetic acid and formic acid presents. The $\mathrm{pH}$ of bio-oil obtained from rice husk was in agreement with $\mathrm{pH}$ of bio-oil produced from corn stover (3.0), big bluestem (3.4) and Praire cord grass (3.6) respectively as reported by [19]. Whereby, [20,21] reported a lower $\mathrm{pH}$ of 2.87 for the bio-oil produced from corn stover through MAP and 2.1 from pine wood respectively. The recorded density value for rice husk is $1.14 \mathrm{gcm}^{-3}$ as shown in Table 4. Rice husk had higher density and compare well with that of [21] who reported $1.138 \mathrm{~g} / \mathrm{cm}^{3}$ for pine wood. Abdullah and Gerhauser [22] described bio-oil as a highly dense liquid with a density around $1.2 \mathrm{gcm}$ 3 , which is in agreement with the values of density obtained for the both samples. Piyarat and Chaiyot, [23] reported $1.18 \mathrm{~g} / \mathrm{cm}^{3} \mathrm{and} 1.10 \mathrm{~g} / \mathrm{cm}^{3}$ as the density of palm shell bio-oil and cassava pulp residue respectively and it is found that the density of pyrolytic sample was higher than that of commercial diesel fuel, which correspond to a higher energy content. The results of the moisture content determination are shown in Table 4. The moisture content of the bio-oil sample for the rice husk is $27.21 \%$. The results obtained are consistent with the result made by Kang et al., [23], he reported that, the moisture content were within the range of $27-38 \%$ was achieved for radiata pine fast pyrolysis in fluidized -bed reactor with a hot vapour filter.

It is also in agreement with many reported results of Oasmaa et al., [24] and also compare well to the palm shell bio-oil [25]. Ash is an impurity that will not burn which reduces handling and burning capacity, it increases handling cost and affects combustion efficiency causes clinkering and slagging. Excessive ash in fuel can cause fouling deposits in the combustion equipment. Ash is the incombustible material, which remains when fuel is burned. Ash is detrimental in combustion processes in which it lowers the calorific value of the fuel. Excessive amounts of ash can causes high wear in pumps and injectors and lead to deposits in combustion equipment [9]. The ash content of the bio-oil sample the rice husk is $0.02 \%$. It was observed that, the ash content of the rice husk bio-oil sample is lesser to that of $0.11 \%$ of pine wood reported by [21] and it could be attributed to the initial ash content of the feedstock. The ash present in the bio-oil can result to corrosion and gumming problems in the engine values. Acidity makes bio-oil very corrosive and extremely severe at elevated temperature, which imposes more requirements on construction materials of the vessels and the upgrading process before using bio-oil in transport fuels. The results of the acid value determination are shown in Table 4. The acid value of the bio-oil sample for the rice husk is $14.48 \mathrm{mg} \mathrm{KOH/g}$. Duration of storage and drying of the biomass can increase the acid value. Kinematic viscosity was observed at $40^{\circ} \mathrm{C}$ for the bio oil produced from rice husk as shown in Table 5. The results are higher than the viscosity of date seed waste $(6.63 \mathrm{cSt}$ ) reported by Mohammed et al., [27] and 1.99 cSt of Coconut shell seed reported by Mohammed et al.,[28]. The high viscosity value of bio oil from rice husk sample will inhibit free flow of the bio oil. Viscosity is a property that represents the flow characteristics of the fuel.

High viscosity in a fuel, leads to several problems such as incomplete combustion, formation of deposits at the tip of injection nozzles and contamination of lubricating oils [29]. The values shown above suggest that, the bio-oil under study require upgrading in order to conform to recommended specification with respect to kinematic viscosity. The result of the flash point is presented in (Table 5) revealed that the flash point value of bio oil from rice husk is 119 ${ }^{\circ} \mathrm{C}$. The results obtained in this report is compared well with (Khor, et al [30] who reported on pyrolysis of oil palm empty fruit bunches in which the flash 
point of their report ranged between $65^{\circ} \mathrm{C}$ to $99^{\circ} \mathrm{C}$. Flash point is a measure of the liquid temperature necessary for the vapors above a pool of the fuel to ignite by passing a flame through the vapors. This is also a measure of the volatility of the oil, as well as its ease of ignition. The higher this number, the safer the oil is to handle, because the risk of accidental vapor ignition is reduced. Pour point is a criterion used for low temperature performance of a fuel. The pour point value of $-12{ }^{\circ} \mathrm{C}$ was recorded which will not cause any trouble in most of the tropical regions and colder regions. The result of this work $(-10$ and $\left.-12{ }^{\circ} \mathrm{C}\right)$ is in agreement or falls with the ASTM range of $\left(-15-\left(-10^{\circ} \mathrm{C}\right)\right)$ and compare well with $-14{ }^{\circ} \mathrm{C}$ and $-17{ }^{\circ} \mathrm{C}$ for palm shell and cassava pulp respectively reported by [23]. High heating value also known to be the gross calorific value for fuel engine is the total amount of heat in a sample of fuel including the energy in the water vapor that is created during the combustion process [31]. The result of this work recorded $40.75 \mathrm{MJ} / \mathrm{Kg}$ for rice husk biooil sample which falls within the ASTM specification $(43 \mathrm{MJ} / \mathrm{Kg}$ ) and the result is higher when compared to the works of palm shell seed oil with 26.93 $\mathrm{MJ} / \mathrm{Kg}$ [23] and date seed oil with $28.63 \mathrm{MJ} / \mathrm{Kg}$ [27].

\subsection{Conclusion}

The influence of process variables on bio-oil production from rice husk using fabricated fixed bed reactor was described by surface response methodology. The best variables condition was achieved for rice husk in a pyrolysis process with a fabricated reactor. The optimum condition was observed at temperature of $650^{\circ} \mathrm{C}$, particle size of $2.03 \mathrm{~mm}$ mesh and reaction time of 81.80 minutes at bio-oil yield of $38.39 \%$. The bio-oil sample had better performance which met the specifications for the measured properties. The optimum conditions obtained would be appropriate for the production of biooil using the fabricated fixed bed reactor. Therefore, using rice husk and other biomass for bio-oil production via pyrolysis process can serve as an approach of providing a sustainable alternative source of fuel and friendly environment.

\subsection{References}

[1] S.H. Kong, S.K. Loh, R.T. Bachmann, S.A. Rahim, and J. Salimon, "Biochar from oil palm biomass; A review of its potential”, Renewable and Sustainable Energy Reviews, Vol. 39, Pp. 729-739, 2014.

[2] S. Nanda, R. Azargohar, J.A. Kozinski, and A.K. Dalai, "Characteristics studies on the pyrolysis products from hydrolyzed Canadian lignocellulosic feedstocks", Bioenergy Resources. 2013. DOI 10.1007/S12155-013-9359-7.

[3] M. Tripathi, J.N. Sahu, and P. Ganesan, "Effects of process parameters on production of biochar from biomass waste through pyrolysis; A review", Renewable and Sustainable Energy Reviews, Vol. 55, Pp. 467-481, 2016.

[4] D. Mohan, C.U. Pittman, and P.H. Steele, “Pyrolysis of wood/biomass for bio-oil: A critical review”, Energy \& Fuels, Vol. 20, Pp. 848-889, 2006.

[5] Q. Lu, Z.F. Zhang, C.Q. Dong, and X.F. Zhu, "Catalytic upgrading of biomass fast pyrolysis vapors with nano metal oxides: An analytical Py-GC/MS study", Energies, Vol. 3, Pp. 1805-1820, 2010.

[6] I.J. Shelley, M. Takahashi-Nosaka, M. Kano-Nakata, M.S. Haque and Y. Inukai, "Rice cultivation in Bangladesh: present, scenario, problems and prospects", Journal of International Cooperation for Agricultural Development, Vol. 14, Pp. 20-29, 2016.

[7] A.D. Pharm, P. Dharanipriya, K.V. Bharath, and M. Shanmugavadivu, "Groundnut Shell- a Beneficial Bio-waste", Biocatalysis and Agricultural Biotechnology, Vol. 20, Pp. 101206, 2019.

[8] N.N. Kasim, A.R. Mohamed, M.A.M. Ishak, R. Ahmad, W.I. Nawawi, K. Ismail, and N.H.M. Salleh, "Optimization of pyrolysis process parameters of torrefied demineralized palm empty fruit bunch (TDEFB) by response surface methodology", AIP Publishing, 2018.

[9] O.Y. Ogunsanwo, and I.A. Adegoke, "Thermo-Chemical Characterization of Bio-Oil Produced from Sawdust of Three Hard Wood Species in Nigeria", Journal of Environmental Extension, Vol. 10 (1), 2011.

[10] O. Harrison and I.A. Rapheal, "Application of Response Design for the Optimization of Biodiesel Production from Desert Date (Balanite aegyptiaca) oil", AASCIT Journal of Energy, Vol.6, No.1, Pp. 1-7, 2019.

[11] ASTM D 1744, "ASTM International Standard Test Method for Determination of Water In Liquid Petroleum Products by Karl Fischer Reagent", 1988 www.astm.org/Standards/D1744.htmD1744 - 13; www.astm.org/Download-D1744.pdf

[12] ASTM D 482-07, "Standard Test Method for Ash from Petroleum Products”, American Society for Testing and Materials, 2007.

[13] ASTM D 4052, "Standard test method for density and relative density of liquids by digital density meter", Easton, MD: American Society for Testing and Materials, 1988.

[14] M.Z. Kyari, “Extraction and Characterization of Seed Oils”, International Agrophysics, Vol. 22, Pp. 139-142, 2008.

[15] ASTM D 396, Specifications of bio-fuels, 2016.

[16] ASTM D445-06, "Standard Test Method for kinematic viscoscity of transparent and opaque liquids”, ASTM Inter. west Conshohocken, PA, 2006.

[17] ASTM D93-08, “Standard Test Method for flash point by Pensky-Martens closed cup tester”, ASTM Inter. west Conshohocken, PA, 2008.

[18] ASTM D97-11, "Standard Test Method for pour point of petroleum products”, ASTM Inter. west Conshohocken, PA, 2011.

[19] K. Muthukumarappan, A. Sivasastri, and C. Karunanithy, "Characteriztion of Biochar and Bio-oil Produced from Different Feedstocks", Journal of Agricultural Machinery Science, 7 (4), Pp. 351-354, 2011.

[20] F. Yu, S. Deng, P. Chen, Y. Wan, A. Olson, D. Kittleson, and R. Ruan, "Physical and Chemical Properties of Bio-oils from Microwave Pyrolyis of Corn Stover”, Applied Biochemistry and Biotechnology, Vol. 136-140, Pp. 957-970, 2007.

[21] S. Thangalazhy-Gopakumar, S. Adhikari, H. Ravindran, R.B. Gupta, O. Fasina, M. Tu, and S.D. Frenando, 2010. "Physicochemical properties of bio-oil produced at various temperatures from pine wood using auger reactor", Bioresource Technology, Vol. 101, Pp. 8389-8395.

[22] N. Abdullah, and H. Gerhauser, “Bio-oil Derived from Empty Fruit Bunches”, Fuel, Vol. 87, No. 12, Pp. 2606-2613, 2008.

[23] W. Piyarat, and T. Chiyot, "Fuel Properties and ChemicalCompositions of Bio-oils from Biomass Pyrolysis", Journal of Society of Automatic Engineers of Japan; JSAE 2007087,SAE 2007-01-2024. 
[24] B. Kang, K.H. Lee, and H.J. Park, "Fast pyrolysis of radiate pine in a bench scale plant with a fluidized bed: Influence of a char separation system and reaction conditions on the production of bio-oil", J. Anal. Appl. Pyrolysis, Vol. 76, Pp. 32-37, 2006.

[25] A. Oasmaa, D.C. Elliott, and S. Muller, "Quality Control in Fast Pyrolysis Bio-oil Production and Use", Environmental Progress and Sustainable Energy, Vol. 28, Pp. 404-409, 2009.

[26] F. Abnisa, A. Arami-Niya, D. Wan, and J.N. Sahu, 2013a. “Characterization of Bio-oil and Bio-char from Pyolysis of Palm Oil Wastes”, BioEnergy Research, Vol. 6, No. 2, Pp. 830-840.

[27] M.A. Sukiran, C.M. Chin, and N.K.A. Bakar, "Bio-oils from Pyrolysis of Oil Palm Empty Bunches," American Journal of Applied Sciences, Vol. 6, No. 5, Pp. 869-875, 2009.

[28] U.H.J. Mohammed, R.I. Mohammad and R.A.B. Mohd, "Proceedings of the International Conference on Mechanical Engineering", ICME2011, Dhaka, Bangladesh, 18-20, 2011.

[29] L.G. Hassan, and N.A. Sani, "Preliminary Studies on Biofuel Properties of Bottle Gourd (Lagenaria siceraria) Seeds Oils", Nigerian Journal of Renewable Energy, Vol. 14, No. 1 \& 2, Pp. 12-15, 2006.

[30] K.H. Khor, K.O. Lim, and Z.A. Zainal, "Characterization of bio-oil: a by-product from slow pyrolysis of oil palm empty fruit bunches", Am. J. of Applied Sci., Vol. 6, Pp. 1647-1652, 2009.

[31] M.M. Azam, A. Waris, and N.M. Nahar, "Prospects and potential of fatty acid methyl esters of some non-traditional seed oils for use as biodiesel in India", Biomass and Bioenergy, Vol. 29, Pp. 293-302, 2005. 